\title{
TBLR1 as an androgen receptor (AR) coactivator selectively activates AR target genes to inhibit prostate cancer growth
}

\author{
Garrett Daniels', Yirong Li', Lan Lin Gellert', Albert Zhou', Jonathan Melamed', \\ Xinyu Wu', Xinming Zhang', David Zhang' ${ }^{2}$, Daniel Meruelo',3, Susan K Logan ${ }^{3,4,5}$, \\ Ross Basch ${ }^{1}$ and Peng Lee ${ }^{1,3,5,6}$ \\ 'Department of Pathology, New York University School of Medicine, New York, New York, USA \\ ${ }^{2}$ Department of Pathology, Mount Sinai School of Medicine, New York, New York, USA \\ ${ }^{3} \mathrm{NYU}$ Cancer Institute, ${ }^{4}$ Department of Urology, ${ }^{5}$ Department of Pharmacology, ${ }^{6} \mathrm{New}$ York Harbor Healthcare \\ System, New York University School of Medicine, New York, New York, USA
}

Correspondence

should be addressed to $P$ Lee who is now at Department of Pathology and Urology, New York Harbor Healthcare System, New York University School of Medicine, $423 \mathrm{E}$. 23rd Street, Room 6139N, New York, New York 10010 USA or R Basch

Emails

peng.lee@nyumc.org or ross.basch@nyumc.org

\begin{abstract}
Androgen receptor (AR), a steroid hormone receptor, is critical for prostate cancer growth. However, activation of AR by androgens can also lead to growth suppression and differentiation. Transcriptional cofactors play an important role in this switch between proliferative and anti-proliferative AR target gene programs. Transducin $\beta$-like-related protein 1 (TBLR1), a core component of the nuclear receptor corepressor complex, shows both corepressor and coactivator activities on nuclear receptors, but little is known about its effects on AR and prostate cancer. We characterized TBLR1 as a coactivator of AR in prostate cancer cells and determined that the activation is dependent on both phosphorylation and $19 S$ proteosome. We showed that TBLR1 physically interacts with AR and directly occupies the androgen-response elements of the affected AR target genes in an androgen-dependent manner. TBLR1 is primarily localized in the nucleus in benign prostate cells and nuclear expression is significantly reduced in prostate cancer cells in culture. Similarly, in human tumor samples, the expression of TBLR1 in the nucleus is significantly reduced in the malignant glands compared with the surrounding benign prostatic glands $(P<0.005)$. Stable ectopic expression of nuclear TBLR1 leads to androgen-dependent growth suppression of prostate cancer cells in vitro and in vivo by selective activation of androgenregulated genes associated with differentiation (e.g. KRT18) and growth suppression (e.g. NKX3-1), but not cell proliferation of the prostate cancer. Understanding the molecular switches involved in the transition from AR-dependent growth promotion to AR-dependent growth suppression will lead to more successful treatments for prostate cancer.
\end{abstract}

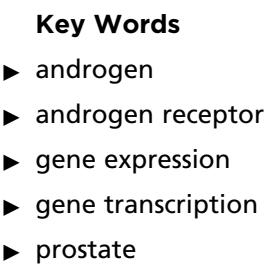

Endocrine-Related Cancer (2014) 21, 127-142
(C) 2014 Society for Endocrinology Printed in Great Britain
Published by Bioscientifica Ltd. 


\section{Introduction}

It has long been known that androgens are critical in the growth and progression of prostate cancer (Dehm \& Tindall 2006). Androgens signal through the androgen receptor (AR), a member of the steroid receptor family of transcription factors that plays an important role in the regulation of genes controlling growth suppression/ differentiation and growth of prostate cells. Androgens activate AR, facilitating its translocation to the nucleus, binding at androgen-response elements (ARE), and interacting with cofactors (coactivators or corepressors), leading to the activation or repression of AR target genes. Although androgen activation leads to increased cell proliferation in the prostate cancer cells, it can also lead to differentiation and growth suppression (Yuan et al. 1993, Whitacre et al. 2002). The specific mechanism responsible for this switch is not well understood, although transcriptional cofactors have been shown to be important in the activation and repression of AR target genes (Janne et al. 2000, Gelmann 2002, Heinlein \& Chang 2002). The presence or absence of these cofactors may control the balance between proliferation and differentiation (Peng et al. 2008a, Ligr et al. 2010). Both ARA70 $\alpha$ and p44/Mep50/WDR77 are AR coactivators that act as androgen-dependent tumor suppressors.

Transducin $\beta$-like-related protein 1 (TBLR1), a transcriptional cofactor, was initially identified as a core component of the nuclear receptor corepressor (NCoR) complex and also coimmunoprecipitates with silencing mediator of retinoic acid and thyroid receptor (SMRT) (Tomita et al. 2004). The NCoR complex also contains the closely related protein TBL1X, and GPS2, IR10, and histone deacetylase 3 (HDAC3) (Yoon et al. 2003). The NCoR complex is responsible for the repression of many different transcription factors, including $\mathrm{AR}$ and other nuclear hormone receptors (NHRs; Burke \& Baniahmad 2000).

As an intrinsic component of the NCoR complex, TBLR1 has been shown to have essential functions as a corepressor. TBLR1 is necessary for targeting of the NCoR complex that binds to histones $\mathrm{H} 2 \mathrm{~B}$ and $\mathrm{H} 4$, preferentially to acetylated histones, allowing for repression via deacetylation by HDAC3 (Yoon et al. 2005). TBLR1 also has been shown to be necessary for the activation of liganded NHRs. Removal of TBLR1 by single-cell microinjection of TBLR1 antibodies leads to the repression of nuclear receptor transcription by $\beta$-gal reporter assay including thyroid receptor (TR), estrogen receptor, retinoic acid receptor (RAR), and peroxisome proliferator-activated receptor $\gamma$ $(\operatorname{PPAR} \gamma)$. This activation is mediated through NCoR and
SMRT, as removal of these proteins by injecting antibody or siRNA rescues the repressive effect. TBLR1, an F-box-likedomain-containing protein, has been shown to recruit ubiquitin ligases to the NHR promoter and target NCoR for ubiquitination and dismissal, allowing for the binding of coactivators (Perissi et al. 2004). In addition, TBLR1 has been shown to be phosphorylated in 293T cells by PKC $\delta$, and the ability to activate NHR transcription by TBLR 1 is dependent on this phosphorylation (Perissi et al. 2008). Recent evidence has also shown that TBLR1 is sumoylated and that this sumoylation is required for the activation of Wnt target genes through $\beta$-catenin (Choi et al. 2011).

In this study, we investigated the role of TBLR1 in the modulation of AR-mediated transcription and prostate cancer growth. We show that TBLR1 is a coactivator of $\mathrm{AR}$ and acts as a tumor suppressor in prostate cancer, consistent with its decreased nuclear expression in human prostate cancer compared with benign glands in clinical samples by immunohistochemistry (IHC). TBLR1 selectively activates AR target genes important for growth suppression and differentiation but not proproliferative AR target genes.

\section{Subjects and methods}

\section{Cell lines and culture}

LNCaP, PC3, and 293T cells were procured from ATCC (Manassas, VA, USA) with authentication documented by short tandem repeat (STR) analysis. RC165, an immortalized benign prostate cell, was obtained from the laboratory of Dr J Rhim (Uniformed Services University of the Health Sciences) (Gu et al. 2005). LNCaP-AI, an androgenindependent derivative of LNCaP, was obtained from the laboratory of Dr A Ferrari (New York University Cancer Institute; Gao et al. 1999). PC3-AR was obtained from the laboratory of Dr Z Wang (MD Anderson Cancer Center; Peng et al. 2008b). RC165, RC170, LNCaP-AI, and PC3-AR were all previously used in published research by our laboratory (Peng et al. 2008b, Li et al. 2009, Ligr et al. 2012). Passages from 5 to 20 of each cell line were used for experiments. LNCaP, LNCaP-AI, PC3, RC165, RC170, and $293 \mathrm{~T}$ cells were maintained in a regular medium (RPMI medium 1640 (High glucose DMEM for 293T) plus 10\% FBS), androgen-free medium (phenol-free RPMI medium with $10 \%$ charcoal-treated FBS), or androgen media (androgen-free medium with $10 \mathrm{nM}$ R1881). The cell lines were maintained at $37^{\circ} \mathrm{C}$ in the presence of $5 \% \mathrm{CO}_{2}$.

Published by Bioscientifica Ltd. 


\section{Luciferase assay}

Luciferase assays were carried out (Peng et al. 2008a) with Lipofectamine (Invitrogen) with four ARE $(4 \times$ ARE) reporter, 10 ng pCDNA-AR, 100 ng reporter, 1 ng pR-LUC internal control plasmids, and varying amounts of pCDNA TBLR1 plasmid or mutants. The cells were treated with androgen media for $24 \mathrm{~h}$ before reading. For the appropriate experiments, the cells were also treated with $1 \mu \mathrm{M}$ Rottlerin or $1 \mu \mathrm{M}$ MG132 for $24 \mathrm{~h}$ before reading. DualLuciferase Reporter Assay System (E1910, Promega) was used according to the manufacturer's instructions.

\section{Coimmunoprecipitation}

Immunoprecipitation was carried out using either antiAR, anti-TBLR1, or M2FLAG agarose antibodies to precipitate complexes. The complexes were incubated overnight at $4{ }^{\circ} \mathrm{C}$. Anti-AR/TBLR1 complexes were then incubated with protein $\mathrm{G}$ beads for $4 \mathrm{~h}$ at $4{ }^{\circ} \mathrm{C}$. The beads/agarose were washed three times with lysis buffer and eluted with $2 \times$ Laemmi loading buffer at $100^{\circ} \mathrm{C}$ for $5 \mathrm{~min}$.

\section{Whole-cell lysates, cell fractionation, and immunoblot analysis}

Whole-cell extracts were prepared from LNCaP, RC165, and PC3 cells containing NLSTBLR1 (TBLR1 with a nuclear localization sequence (NLS) tag), pBabe, or native lysates in RIPA buffer (50 mM Tris-HCl, pH 8.0, $150 \mathrm{mM} \mathrm{NaCl}, 1 \%$ NP-40, $1 \mathrm{mM}$ EDTA, and 0.1\% SDS). For cell fractionation, cells were lysed with cytoplasmic buffer (10 mM HEPES, $\mathrm{pH}$ 7.6, $50 \mathrm{mM} \mathrm{NaCl}, 0.5 \mathrm{M}$ sucrose, $1 \mathrm{mM}$ dithiothreitol, $5 \mathrm{mM}$ $\mathrm{MgCl}_{2}$, and $0.1 \%$ Triton X-100). After centrifugation, the supernatant could be retained as the cytoplasmic fraction and the nuclear pellet was washed three times with cytoplasmic buffer followed by lysis with RIPA buffer. The extracts were subjected to electrophoresis on SDS-PAGE and then transferred to nitrocellulose membranes for immunoblot analysis as described by Li et al. (2009) with antibodies for TBLR1 and ERK2 (Santa Cruz Antibodies (Dallas, TX, USA)), $\beta$-actin and anti-FLAG M2 (Sigma (St. Louis, MO, USA)), H2B and GAPDH (Cell Signaling (Danvers, MA, USA)), KRT18, NKX3-1, p21, p27, HUS1, and JAG1 (Abcam (Cambridge, MA, USA)).

\section{Immunofluorescence microscopy}

The cells were fixed in $4 \%$ paraformaldehyde (PFA) for $20 \mathrm{~min}$ and permeabilized in 1:1 methanol:acetone for $20 \mathrm{~min}$. The cells were incubated in 1:100 TBLR1 antibody in $10 \%$ sheep serum overnight, washed with PBS, and incubated in anti-mouse IgG-Cy2-conjugated antibodies (Molecular Probes (Grand Island, NY, USA) 1:500 in 10\% sheep serum) for $1 \mathrm{~h}$, washed with PBS, and counterstained with 4',6-diamidino-2-phenylindole (DAPI) or Hoechst for 2 min as described previously (Li et al. 2009).

\section{Tissue microarray construction and IHC}

The study protocol was approved by the New York University Institution Review Board. An IHC study with antibody against TBLR1 was used to characterize the expression pattern of TBLR1 in prostate cancer. Whole tissue sections from 30 cases of prostatic adenocarcinoma were studied. TBLR1 nuclear and cytoplasmic expression was compared between malignant glands and the surrounding benign prostatic glands on the same slide. The intensity of nuclear and cytoplasmic TBLR1 expression was scored semiquantitatively; 0 as negative, 1 as weak, 2 as moderate, and 3 as strong expression. The score represents the overall level of TBLR1 immunoreactivity including staining intensity and the percentage of positive cells. The nuclear staining and cytoplasmic staining were scored separately. The nuclear and cytoplasmic expression pattern of TBLR1 was studied in 86 prostatic adenocarcinoma samples on a tissue microarray (TMA). Each sample is represented by four $0.6 \mathrm{~mm}$ cores on the TMA. The samples on the TMA were stratified by various clinicopathological factors including age at diagnosis, preoperative PSA, grade, and stage.

\section{Construction of retroviral pBabe vectors expressing NLSTBLR1 to construct stable cell lines}

We created a TBLR1 fusion protein in which the strong NLS PKKKRKV was fused to the $\mathrm{N}$ terminus of TBLR1 to create NLSTBLR1. A retroviral-based mammalian expression vector, pBabe, was used to stably express NLSTBLR1 proteins in LNCaP cells as described previously (Peng et al. 2008a). Briefly, Phoenix A amphotropic packaging cells (American Type Culture Collection (ATCC)) were transfected with NLSTBLR1 and pBabe retroviral constructs to produce virus. The viruscontaining supernatant was collected by centrifugation and filtered before retroviral infection. Stable cell lines were selected in $1 \mu \mathrm{g} / \mathrm{ml}$ puromycin.

\section{Cell proliferation assays}

For cell proliferation assay by WST1 (Roche), cells $\left(1 \times 10^{4}\right)$ were plated into 24 -well plates and measured at A450 every other day. For cell proliferation assays, cells $\left(4 \times 10^{4}\right)$

Published by Bioscientifica Ltd. 
were plated into six-well plates and counted with a hemocytometer every other day, as described previously (Peng et al. 2008a).

\section{Flow cytometry and apoptosis assay}

The cells were grown in six-well plates and were dissociated with trypsin, resuspended in HBSS, and fixed in ice-cold $70 \%$ ethanol. The cells were incubated in propidium iodide/RNAse solution (1 $\mathrm{mg}$ propidium iodide, $10 \mathrm{mg}$ EDTA, $250 \mu 1$ Igepal, and $1 \mathrm{ml}$ of $10 \mathrm{mg} / \mathrm{ml}$ RNAse dissolved in $50 \mathrm{ml} \mathrm{PBS}$ ) at $37^{\circ} \mathrm{C}$ for $2 \mathrm{~h}$. The cell-cycle analysis was performed on a FACSC flow cytometer (BD Biosciences (Bedford, MA, USA)) and analyzed using Weasel Software (The Walter and Eliza Hall Institute of Medical Research, Melbourne, VIC, Australia). For measurement of apoptosis, Promega Apo-ONE homogeneous caspase 3/7 assay was used as per the manufacturer's instructions. The cells were incubated in $10 \mathrm{nM}$ R1881 media for $24 \mathrm{~h}$ before addition of reagent for $18 \mathrm{~h}$ incubation.

\section{RNA isolation and qRT-PCR}

Total RNA was extracted from the cell lines using RNAqueous-4PCR Kit (AM1914, Ambion). A RetroScript Kit (AM1710, Ambion) was used for cDNA synthesis with isolated RNA as template, according to the manufacturer's instructions. RNA was isolated from LNCaP NLSTBLR1 and LNCaP pBabe cells after $48 \mathrm{~h}$ of hormone-free incubation, followed by $24 \mathrm{~h}$ of stimulation by $10 \mathrm{nM}$ R 1881 . Primers for qPCR were kindly donated by Dr S K Logan as reported previously (Nwachukwu et al. 2009). PCR was carried out using the Bio-Rad CFX96 machine and Bio-Rad iQ SYBR Green supermix.

\section{Gene knockdown by siRNA}

siRNAs for AR, TBLR1, and control siRNA were purchased from Ambion and transfected with HiperFect Transfection Reagents (Qiagen) $48 \mathrm{~h}$ before immunoblot analysis of whole-cell extract, RNA extraction, or cell kinetic studies.

\section{Anchorage-independent growth}

LNCaP NLSTBLR1 and pBabe control were seeded into $0.35 \%$ agarose media, containing 10\% charcoal-stripped FBS with $10 \mathrm{nM}$ R1881 or ethanol vehicle at $4 \times 10^{4}$ cells $/ 60 \mathrm{~mm}$ plate. Fresh $0.35 \%$ agarose media was added every 3 days and colonies were allowed to grow for 3 weeks as described previously (Cai et al. 2008). The average number of colonies of the three duplicate plates is displayed. Pictures were taken of representative colonies for each condition.

\section{Chromatin immunoprecipitation}

The LNCaP cells were grown in androgen-free media for $72 \mathrm{~h}$ before $4 \mathrm{~h}$ of stimulation in $10 \mathrm{nMR} 1881$ or ethanol vehicle. The cells were cross-linked for $10 \mathrm{~min}$ in 1\% formaldehyde solution, followed by quenching with $0.125 \mathrm{M}$ glycine. The cells were washed in PBS and lysed in 0.5\% NP-40, 0.25\% Triton X-100, 50 mM HEPES, pH 7.5, 10\% glycerol, $140 \mathrm{mM}$ $\mathrm{NaCl}$, and $1 \mathrm{mM}$ EDTA. Nuclei were resuspended in $50 \mathrm{mM}$ Tris-HCl, pH 8, 10 mM EDTA, and 1\% SDS and sonicated four times for $10 \mathrm{~s}$ each. Twenty five microgram of chromatin was used for each immunoprecipitation (IP) reaction: $2 \mu \mathrm{g}$ of TBLR1, AR, or rabbit IgG antibody was used and incubated overnight at $4{ }^{\circ} \mathrm{C}$. The samples were incubated with Protein $\mathrm{G}$ beads for $4 \mathrm{~h}$ at $4{ }^{\circ} \mathrm{C}$ and washed five times in wash buffer. Immunoprecipitated complexes containing DNA were eluted in 1\% SDS-Tris buffer and reverse crosslinked at $65^{\circ} \mathrm{C}$ overnight. Quantitative PCR was carried out using the BioRad CFX96 machine and Biorad iQ SYBR Green supermix. Cycling conditions were $95{ }^{\circ} \mathrm{C}$ for 10 minutes, followed by 40 cycles of $95^{\circ} \mathrm{C}$ for 15 seconds and $60^{\circ} \mathrm{C}$ for 1 minute. The primer sets used were NKX3-1 ARE I: F, GATGGGTGGGAGGAGATGA; R, TGTCTTGGACAAGCGGAG; NKX3-1 ARE II: F, GGTTCTGCTGTTACGTTTG; R, CTTGCTTGCTCAGTGGAC; HUS1 ARE: F, CTGCTGCTTCTCCTGCTTTT; R, CCACAGAGACCAGGGTGAGT; and GAPDH 3'-UTR: F, ATGGTTGCCACTGGGGATCT; R, TGCCAAAGCCTAGGGGAAGA.

\section{Nude mouse xenografts}

Male nude mice (5 weeks old) were purchased from NCI (Frederick, MD, USA) and maintained in accordance with the Institutional Animal Care and Use Committeeapproved protocol. Ten million cells were used for s.c. injection into the flank region of the mice with Matrigel ECM (reconstituted basement membrane) to support tumor growth. Each experimental group contained ten mice. Tumors were measured with calipers two times per week as described previously (Ligr et al. 2010). At the end of the experiment, tumors were removed and weighed.

\section{Site-directed mutagenesis}

Point mutations in pCDNA TBLR1 and pBabe NLSTBLR1 were made using the Stratagene Quikchange XL (200521)

Published by Bioscientifica Ltd 
mutagenesis kit as described previously (Cai et al. 2008). Mutation 1 is S123-A123 and mutation 2 is S199, T203, S204-A199, A203, A204 respectively.

\section{Statistical analysis}

Statistical analyses of the above results were performed by Student's $t$-test. ${ }^{*} P<0.05,{ }^{* *} P<0.01$, and ${ }^{* * *} P<0.001$. Differences are considered statistically significant if $P<0.05$.

\section{Results}

\section{TBLR1 functions as an AR coactivator in prostate cancer cells}

Although initially identified as a core component of the NCoR corepressor complex and necessary for repression of TR, TBLR1 has also been found to be important in the activation of several transcription factors, including but not limited to, RAR, PPAR $\gamma$, and nuclear factor kappa B (NF-кB) (Perissi et al. 2004). We examined the role of TBLR1 in AR-mediated transcription using a dual luciferase assay, with a luciferase reporter containing $4 \times \mathrm{ARE}$ and $\mathrm{pRL}$ Renilla internal control reporter in PC3 (AR negative) prostate cancer cells in the presence of synthetic androgen, $\mathrm{R} 1881$. In the absence of androgen or AR, increased TBLR1 expression had no effect on reporter activity. However, after transfection with AR, TBLR1 lead to up to 2.5-fold increase in AR activation in a dose-dependent manner (Fig. 1A).

We next determined if there was a physical interaction between AR and TBLR1. First, we overexpressed a FLAG-tagged AR plasmid or a GFP control plasmid in 293T cells. Using FLAG antibody to immunoprecipitate and immunoblotting for TBLR1, we identified an interaction between AR and TBLR1 (Fig. 1B1). Next, to confirm this interaction in prostate cancer cells, we used AR-positive LNCaP cells stably overexpressing NLSTBLR1. We used TBLR1 antibody for immunoprecipitation and AR for immunoblotting. The cells were grown in androgen-free media for $48 \mathrm{~h}$ before stimulation with $10 \mathrm{nM}$ R1881 or ethanol vehicle for $6 \mathrm{~h}$. We observed interaction between the two proteins in prostate cancer cells in the presence of R1881 (Fig. 1B2). In addition, we carried out the experiment in a reciprocal manner, using $\mathrm{AR}$ antibody to immunoprecipitate and TBLR1 antibody to probe to confirm the physical interaction (Fig. 1B3). Finally, to test this interaction in an endogenous system without any overexpression, we used the LNCaP-AI cell line. LNCaP-AI cells are an androgen-independent derivative of LNCaP cells that still express AR and are sensitive to androgens.
By immunoprecipitation with AR antibody and immunoblotting for TBLR1, we were also able to observe the interaction between TBLR1 and AR in an androgendependent manner (Fig. 1B4).

\section{Posttranslational modifications important for TBLR1 action on AR-mediated transcription}

Several posttranslational modifications affect TBLR1 activity (Perissi et al. 2004, 2008). The ability of TBLR1 to activate RAR is dependent both on $19 \mathrm{~S}$ proteosome and PKC $\delta$ phosphorylation. Phosphorylation sites of TBLR1 are marked on the diagram in Fig. 1C. Upon phosphorylation at S123 and/or S199/T203/T204, TBLR1 targets NCoR for ubiquitination and dismissal in the activation of RAR (Perissi et al. 2008). We tested if this was also true in the case of TBLR1 acting as a coactivator of AR in prostate cancer cell growth. In the presence of a specific 19S proteosome inhibitor, MG132, a specific PKC inhibitor, Rottlerin, or mutant TBLR1 constructs, S123A, S199A/T203A/T204A, or the double mutant TBLR1 activation of AR was diminished up to threefold (Fig. 1D, $\mathrm{E}$ and F). We found that mutation of site 1, site 2, or both had the same diminished transcriptional effect, suggesting that both sites are involved in transcriptional activation. It is important to note that the phospho-mutant TBLR1 plasmids did retain partial activation ability. We also performed a parallel western blot to check the overall NCoR levels and confirm overexpression of TBLR1 after transfection with WT TBLR1 and the mutant constructs (Fig. 1F). However, we found no variations in total NCoR levels among each condition.

Sumoylation is another posttranslational modification reported to affect TBLR1 activity (Choi et al. 2011). However, the mutation of the critical site for sumoylation K497 did not affect its AR-mediated transcriptional coactivator activities in our luciferase assay (Supplementary Fig. 1A, see section on supplementary data given at the end of this article).

\section{TBLR1 expression and subcellular localization in prostate cancer}

Altered cofactor expression and localization have been shown to correlate with prostate cancer (Peng et al. 2008a, Ligr et al. 2010). In this study, we have examined the expression levels and intracellular localization of TBLR1 in benign and malignant prostate cell lines and human tissue.

Published by Bioscientifica Ltd. 

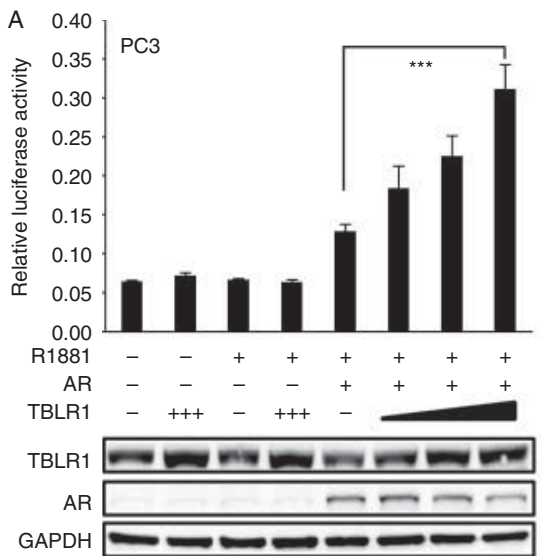

B

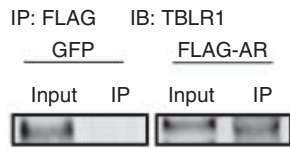

2
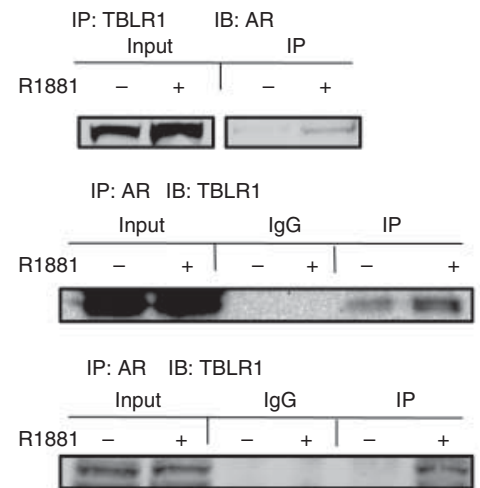

C

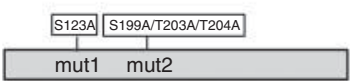

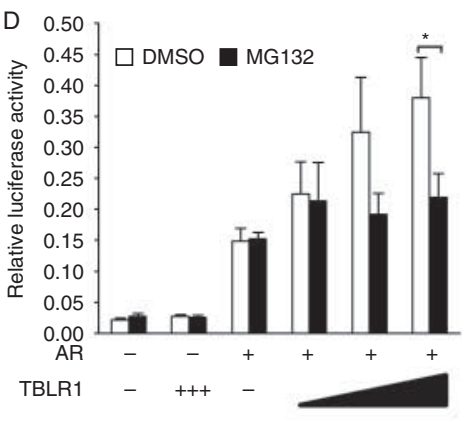
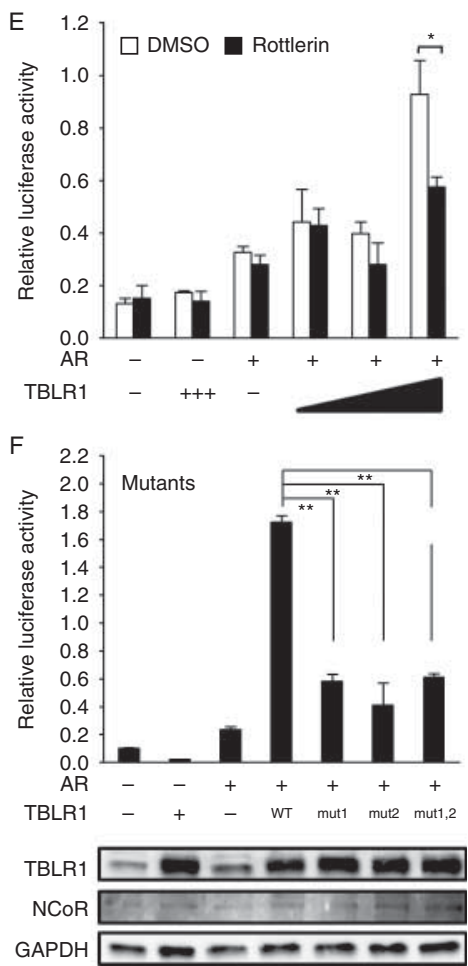

in LNCaP-AI cells. IP, immunoprecipitation; IB, immunoblotting. (C) Diagram of previously identified phosphorylation sites important for coactivator activity in TBLR1. (D) Treatment with the proteosome inhibitor MG132 reduces the ability of TBLR1 to activate AR-mediated transcription in the presence of $10 \mathrm{nM}$ R1881. (E) Treatment with the PKC inhibitor Rottlerin also reduces the ability of TBLR 1 to activate $A R$ in the presence of $10 \mathrm{nM}$ R1881. (F) Mutant TBLR1 constructs, mut1 with S123A, mut2 with S199A/T203A/T204A, or double mutants show reduced ability to activate AR-mediated transcription in the presence of $10 \mathrm{nM}$ R1881. All experiments were performed in triplicate. ${ }^{*}, P<0.05, * *, P<0.01, * * *, P<0.001$.

We confirmed these results by western blot with cellular fractionation (Fig. 2C). To further confirm variable levels of nuclear TBLR1 expression in benign vs malignant prostate cancer cells, we also tested protein levels in two additional androgen-sensitive cell lines, benign RC170 cells and malignant LNCaP-AI cells, relative to LNCaP cells with cell fractionation followed by western blot (Supplementary Fig. 2A, see section on http://erc.endocrinology-journals.org DOI: 10.1530/ERC-13-0293
(C) 2014 Society for Endocrinology Printed in Great Britain 
A

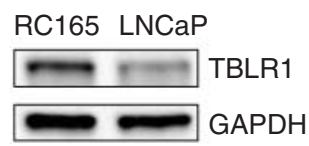

B
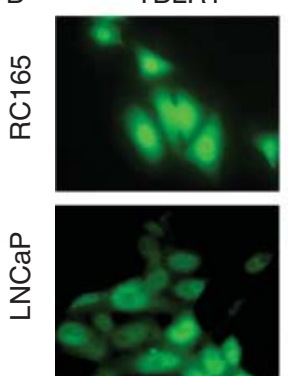

C

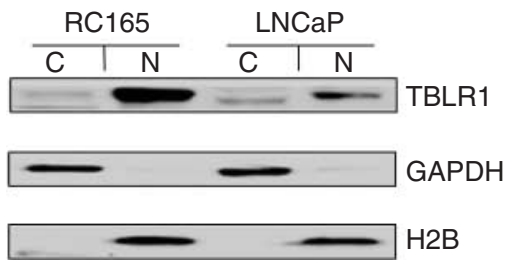

DAPI
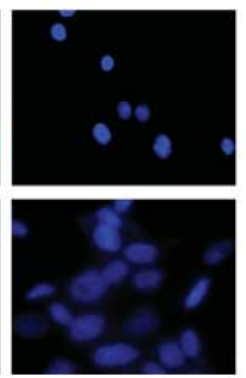

D

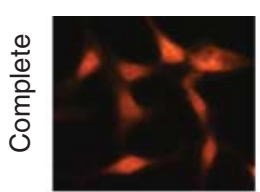

E
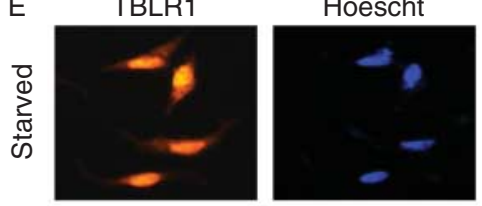

$\mathrm{F}$

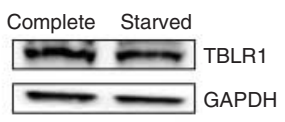

G

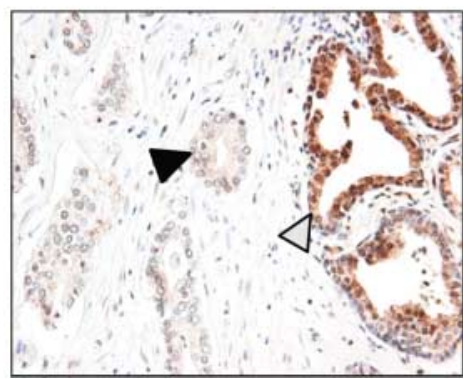

Figure 2

Expression of TBLR1 in prostate cancer. (A) TBLR1 expression in immortalized benign prostate RC165 is high compared with malignant LNCaP cells by western blot. GAPDH is used as a loading control. (B) Cytolocalization of TBLR1 by immunoflourescence shows primarily nuclear in RC165 and both nuclear and cytoplasmic in LNCaP. (C) Confirmation of cytolocalization of TBLR1 in RC165 and LNCaP cells by cell fractionation followed by western blot. (D) In complete media, TBLR1 is primarily located in the cytoplasm of LNCaP-Al cells, but induced growth arrest upon $16 \mathrm{~h}$ serum starvation

supplementary data given at the end of this article). Consistently, benign RC170 cells showed high nuclear TBLR1 and malignant LNCaP-AI showed low nuclear TBLR1 levels.

It has previously been shown that TBLR1 translocates to the nucleus upon serum starvation in NIH 3T3 cells (Zhang et al. 2006). These results, combined with the fact that we observed higher nuclear TBLR1 expression in benign RC165 vs malignant LNCaP cells, indicated that nuclear TBLR1 conveyed a growth arrest signal. To test if this phenomenon was true in the prostate, LNCaP-AI cells were serum starved for $16 \mathrm{~h}$ in $0.2 \%$ FBS. Serum-starved LNCaP-AI cells showed increased nuclear and reduced cytoplasmic staining compared with cells grown in normal 10\% FBS growth media (Fig. 2D and E). Serumstarvation-induced growth arrest did not lead to changes in overall TBLR1 expression (Fig. 2F). leads to E. TBLR1 migration to the nucleus. (F) Total levels of TBLR1 do not change after serum-starvation-induced growth arrest. (G) In human prostate cancer tissue, TBLR1 expression is lower in malignant glands (black triangle) compared with neighboring benign glands (white triangle) by immunohistochemistry. Picture is a representative sample from the 19 of 30 tissue samples showing reduced nuclear TBLR1 expression in malignant glands. Full colour version of this figure available via http://dx.doi.org/ 10.1530/ERC-13-0293.

We next looked at TBLR1 expression in human prostate cancer tissue samples. TBLR1 nuclear and cytoplasmic expression was measured by IHC using whole tissue sections from 30 cases of prostatic adenocarcinoma. TBLR1 nuclear and cytoplasmic expression was compared between malignant glands and the surrounding benign prostatic glands on the same slide.

Comparing malignant glands with the surrounding benign prostatic glands on the same tissue section, the expression of TBLR1 in nucleus is significantly lower in the malignant glands ( $P<0.005$; Fig. 2G). Among the 30 cases of prostatic adenocarcinoma we studied, the levels of TBLR1 nuclear expression in malignant glands: decreased in 19 cases, was unchanged in ten cases, and increased in one case (Table 1). In addition, TBLR1 nuclear and cytoplasmic expression patterns were studied in 86 samples of prostatic adenocarcinoma on a TMA. When stratified with

Published by Bioscientifica Ltd 
Table 1 Expression of nuclear TBLR1 in prostate cancer

\begin{tabular}{lc}
\hline \multicolumn{1}{c}{ TBLR1 nuclear staining (malignant vs adjacent benign gland) } \\
${$\cline { 1 - 1 }$} }$ & No. of cases \\
\cline { 1 - 2 } Decreased & 19 \\
Unchanged & 10 \\
Increased & 1 \\
Total & 30 \\
\hline
\end{tabular}

Thirty cases of prostate cancer were stained for TBLR1 by immunohistochemistry in which both malignant and benign glands could be observed on the same slide. Benign and malignant cells were scored based on overall level of TBLR1 immunoreactivity including staining intensity and the percentage of positive cells in each sample. Data in the table indicate the number of the malignant glands vs benign glands samples that exhibited decreased, unchanged, or increased levels of TBLR1 nuclear expression.

clinicopathological factors, the levels of TBLR1 nuclear expression have a positive correlation with the Gleason scores $\left(R^{2}=0.9621, P<0.01\right.$; Supplementary Fig. 2C). We also tested 14 additional cases with high-grade prostatic intraepithelial neoplasia (HGPIN), a precursor lesion of prostate cancer, adjacent to benign prostate glands on the same section. The data indicated decreased TBLR1 expression in ten of 14 cases (71\%) of HGPIN (Supplementary Table 1 and Supplementary Fig. 2B). No statistically significant difference between the level of TBLR1 cytoplasmic expression in malignant prostatic glands and that in the benign prostatic glands was observed.

\section{Nuclear TBLR1 inhibits prostate cancer growth in vitro}

To study the functional effects of nuclear TBLR1 in prostate cells, we aimed to overexpress nuclear TBLR1 in LNCaP cells and measure its effects. In order to achieve nuclear localization of exogenenous TBLR1 expression, we created an NLSTBLR1 (containing a nuclear localization sequence PKKKRKV) fusion construct. GFP-NLSTBLR1 was confirmed to localize to the nucleus upon transfection into $293 \mathrm{~T}$ cells (Supplementary Fig. 3A, see section on supplementary data given at the end of this article). In comparison, GFP-TBLR1 (WT) construct expression was exclusively observed in the cytoplasm (Supplementary Fig. 3B). Control cells were made using the pBabe vector alone. Overexpression of NLSTBLR1 is shown both at the RNA and protein level (Fig. 3A). We also confirmed that overexpression of nuclear TBLR1 had no effect on AR protein levels in these cells (Supplementary Fig. 3C). Nuclear TBLR1 dramatically reduced proliferation of $\mathrm{LNCaP}$ cells in $10 \mathrm{nM}$ R1881 media and also showed reduced proliferation in hormonefree media (Fig. 3B), although the degree of inhibition is more substantial in androgen-containing media. The cellcycle analysis by flow cytometry revealed that overexpression of nuclear TBLR1 in androgen-containing media led to a twofold decrease in S-phase cells, suggesting a G0/G1 arrest mechanism as the cause of reduced proliferation (Fig. 3C). Similar findings were observed in hormone-free media as well (data not shown). We found no evidence of increased apoptosis in LNCaP NLSTBLR1 compared with LNCaP pBabe in $10 \mathrm{nM}$ R1881 media, using a caspase 3/7 activity assay (Supplementary Fig. 3D). We found similar proliferative effects of nuclear TBLR1 with both 1 and 10 nM R1881 (Supplementary Fig. 4A, B, C and D, see section on supplementary data given at the end of this article). In addition, we performed TBLR1 silencing with siRNA to test the effects on proliferation and cell cycle. Interestingly, loss of TBLR1 expression in LNCaP cell lines led to dramatic decrease in growth and G0/G1 cell-cycle arrest (Supplementary Fig. 5B and C). TBLR1 knockdown in LNCaP-AI cells also led to decreased growth and G0/G1 cell-cycle arrest (Supplementary Fig. 5D and E).

To test effect of nuclear TBLR1 on cellular transformation, we performed an anchorage-independent growth assay in soft agar, comparing LNCaP cells expressing NLSTBLR1 or control vector. After 14 days, significantly fewer colonies were observed in cells overexpressing NLSTBLR1. In hormone-free media, colony numbers of cells expressing NLSTBLR1 were reduced to 75\%, and in androgencontaining media they were reduced to $67 \%$ (Fig. 3D). In addition, the average size of colonies was reduced as shown in representative pictures of colonies (Fig. 3E). Thus, increased nuclear TBLR1 not only led to reduced growth of LNCaP cells but also inhibited their anchorage-independent growth, an in vitro assay of transformation.

In addition, we created LNCaP cell lines expressing NLSTBLR1 phospho-mutants as described earlier; however, the growth inhibitory function of nuclear TBLR1 was not affected by either mutations (Supplementary Fig. 3E).

\section{Nuclear TBLR1 suppresses prostate tumor growth in vivo}

To determine if the inhibitory effect of nuclear TBLR1 on growth in culture could be replicated in vivo, we examined tumor growth in subcutaneous nude mouse xenografts with LNCaP pBabe and LNCaP NLSTBLR1 cells (Fig. 4A and $B)$. In ten mice of each group, $1 \times 10^{7}$ cells were injected s.c. into the right flank and measured twice per week. Tumors produced by LNCaP pBabe cells exhibited steady growth over the 10-week time course of the experiment. However, tumors produced by LNCaP NLSTBLR1 cells exhibited minimal growth over the same time period (Fig. 4C). Two separate single clones of LNCaP NLSTBLR1 were used to confirm the inhibitory effect of

Published by Bioscientifica Ltd. 
A
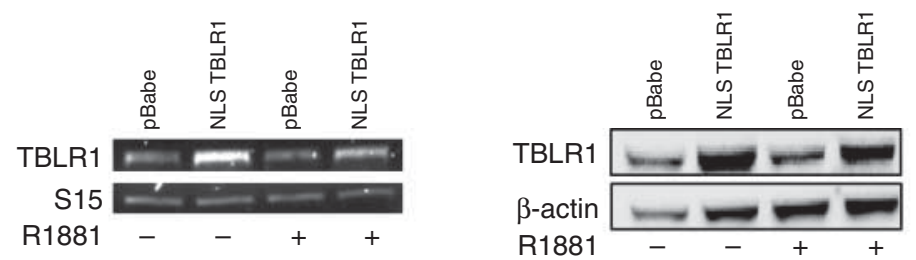

B
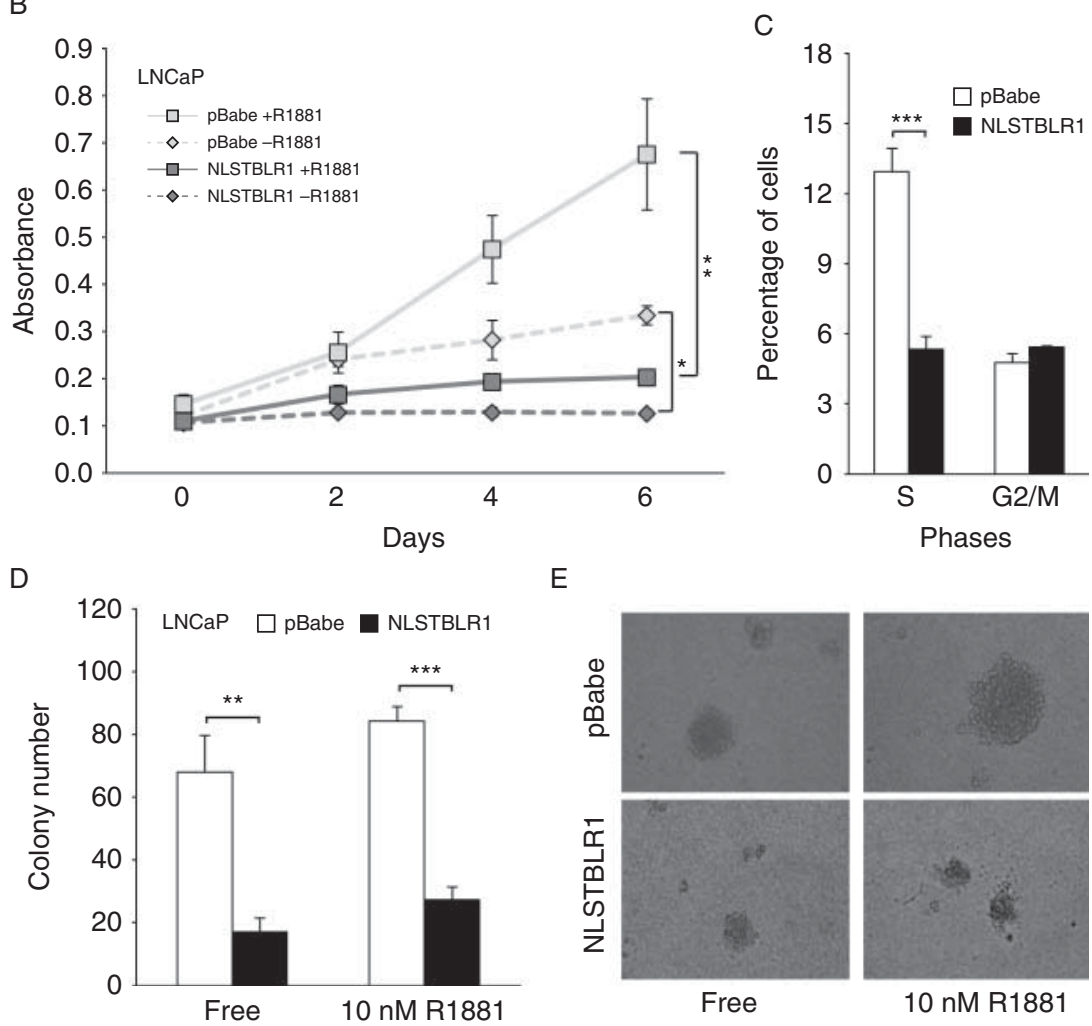

Figure 3

Effect of nuclear TBLR1 on in vitro prostate cancer cell growth. (A) Expression of TBLR1 by RT-PCR and western blot of LNCaP NLSTBLR1 stable line compared with LNCaP pBabe control. (B) WST1 proliferation assay of LNCaP NLSTBLR1 compared with $\mathrm{LNCaP}$ pBabe control shows reduced growth in both hormone free and 10 nM R1881 media. (C) Cell-cycle analysis with PI staining by flow

nuclear TBLR1 on in vivo growth. After the 10-week time course, tumors were harvested and weighed. Weight of LNCaP pBabe tumors was significantly higher than that of LNCaP NLSTBLR1 tumors (Fig. 4D). IHC staining of xenograft tumors confirmed increased TBLR1 expression in the NLSTBLR1 tumors compared with pBabe control by IHC (Fig. 4E and F). There is a strong increase in the tumor suppressor $N K X 3-1$, an AR target gene, reactivity in NLSTBLR1 tumors compared with pBabe control (Fig. 4E and F). There was no difference in cleaved Caspase 3 levels between NLSTBLR1 and control tumors (Supplementary Fig. 7A and B, see section on supplementary data given at the end of this article), consistent with our in vitro data (Supplementary Fig. 3D). cytometry comparing LNCaP pBabe to LNCaP NLSTBLR 1 in 10 nM R1881 media. (D) Anchorage-independent growth assay displaying the average number of colonies observed per plate in LNCaP pBabe and LNCaP NLSTBLR1 in hormonefree and $10 \mathrm{nM}$ R 1881 media. (E) Representative pictures of colonies in anchorage-independent growth assay. ${ }^{*}, P<0.05, * *, P<0.01, * * *, P<0.001$.

\section{AR-dependence of nuclear TBLR1 function on prostate cancer growth suppression}

To test if the effect of nuclear TBLR1 on prostate cancer cell growth is mediated through AR, we created cell lines expressing NLSTBLR1 in PC3 cells, an AR-negative prostate cancer cell line, and PC3-AR, a derivative of PC3 expressing WT AR. Increased nuclear TBLR1 slightly increased growth in AR-negative PC3 cells in $10 \mathrm{nM}$ R1881 media, (Fig. 5A) but PC3-AR cells expressing NLSTBLR1 exhibited reduced growth in $10 \mathrm{nM}$ R1881 media (Fig. 5B). In hormone-free media, PC3-AR NLSTBRL1 cells exhibited a slightly increased growth rate compared with PC3-AR control cells (Supplementary

Published by Bioscientifica Ltd. 
A

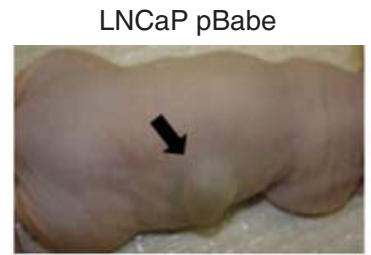

C

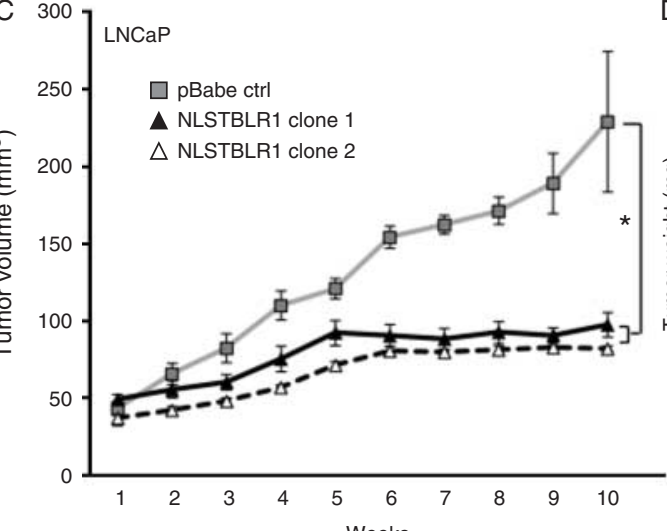

$E$
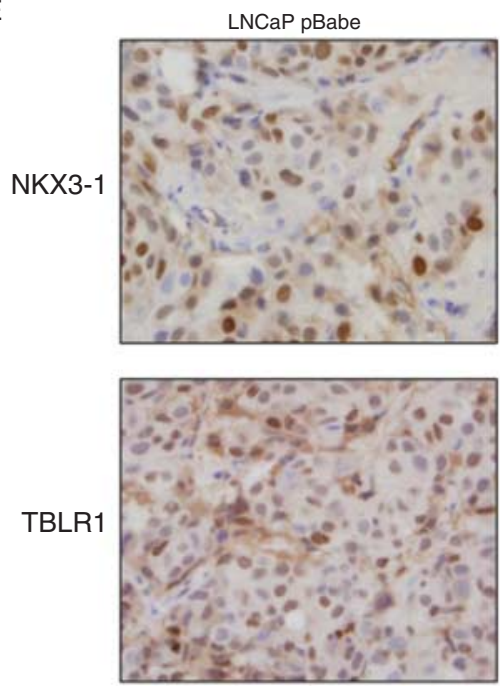

B
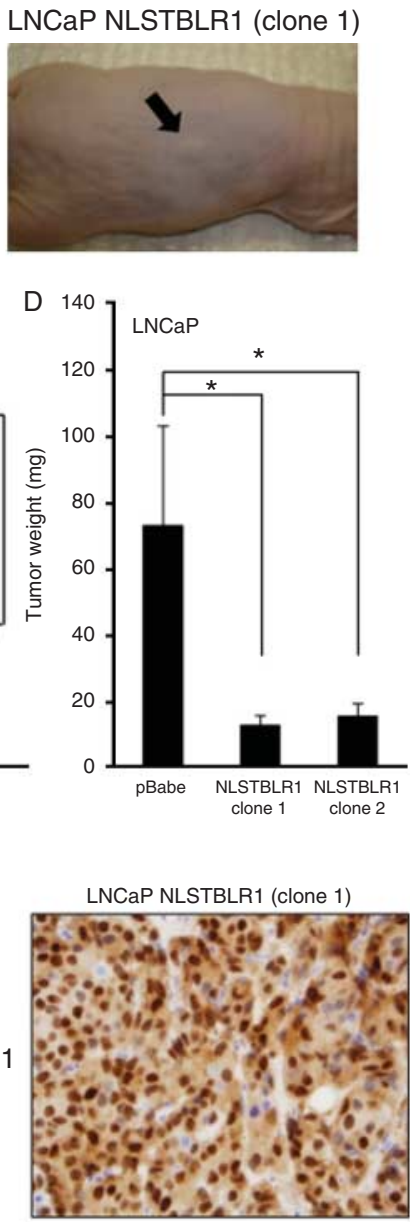

TBLR1

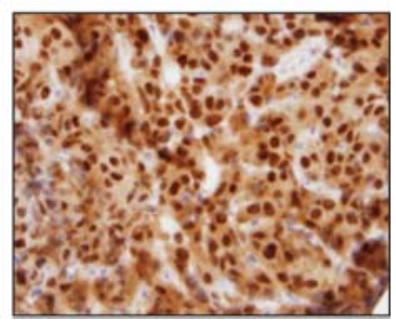

\section{Figure 4}

Nuclear TBLR1 inhibits in vivo prostate cancer growth. (A) Representative pictures of subcutaneous tumor xenografts from LNCaP pBabe and (B) LNCaP NLSTBLR1 clone 1 groups. (C) Growth suppression by nuclear TBLR1 on subcutaneous tumor xenografts, Tumor volume over 10 weeks showing LNCaP NLSTBLR1 cells having greatly reduced in vivo tumor growth. Grey squares, control LNCaP pBabe cells; black triangles, LNCaP

Fig. 6A, see section on supplementary data given at the end of this article) similar to what we have observed in PC3-NLSTBLR1 cells in androgen media (Fig. 5A). Although AR-transfected PC3 cells lines primarily show a negative growth response to androgen (Yuan et al. 1993, Garcia-Arenas et al. 1995), more recently it has been observed that the level of AR expression can modulate
NLSTBLR1-clone 1 cells; and white triangles, LNCaP NLSTBLR1-clone 2 cells. (D) Average tumor weights from harvested tumors after 10 weeks; Error bars represent S.E.M. (E) IHC on LNCaP pBabe tumor for NKX3-1 and TBLR1. (F) IHC on LNCaP NLSTBLR1 clone 1 tumor for NKX3-1 and TBLR1. * $P<0.05$. Full colour version of this figure available via http://dx.doi.org/10.1530/ERC13-0293.

the androgen response in these cells (Altuwaijri et al. 2007, $\mathrm{Yu}$ et al. 2009). The PC3-AR cell line used in our experiments showed a slight increase in growth rate upon stimulation with $10 \mathrm{nM}$ R1881 compared with hormone-free media (Supplementary Fig. 6B).

In addition, we examined the effects of loss of AR using AR knockdown with siRNA in LNCaP pBabe control

Published by Bioscientifica Ltd. 

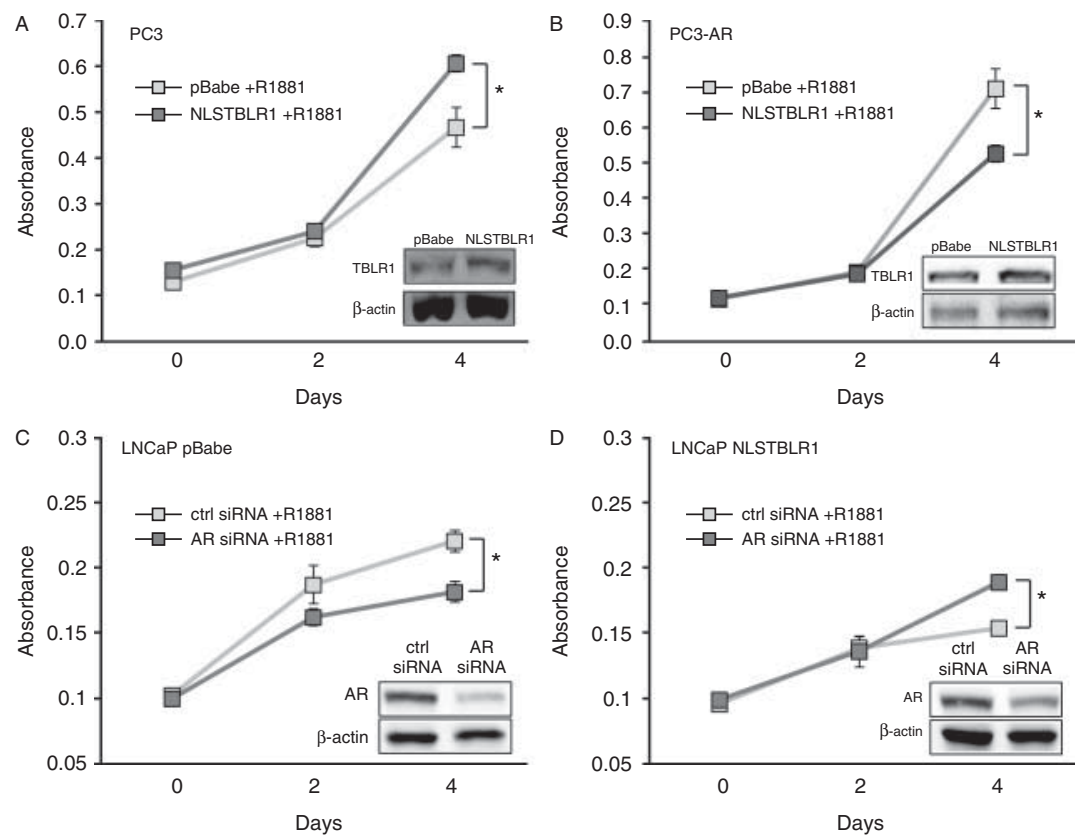

Figure 5

AR-dependence of nuclear TBLR1 growth inhibition. (A) Proliferation assay of PC3-NLSTBLR1 compared with PC3-pBabe control shows increased growth in $10 \mathrm{nM}$ R1881 media. (B) Proliferation assay of PC3-AR-NLSTBLR1 compared with PC3-AR-pBabe control shows decreased growth in $10 \mathrm{nM}$ R1881 media. (C) Proliferation assay of LNCaP pBabe cells treated with AR

cells (Fig. 5C) and LNCaP NLSTBLR1 cells (Fig. 5D), followed by cell proliferation assays. AR knockdown on LNCaP pBabe control cells reduced growth while AR knockdown in LNCaP NLSTBLR1 stimulated growth, partially reversing the negative growth effects of overexpressed nuclear TBLR1. Together, these data indicate that there is at least partial AR-dependence for nuclear TBLR1 suppression of prostate cancer growth.

\section{Selective regulation of AR target genes by nuclear TBLR1}

Because TBLR1 acts as a coactivator for AR in prostate cancer cells in a luciferase reporter assay and alterations in nuclear TBLR1 expression led to growth arrest, we sought to determine what specific AR-responsive genes were regulated by TBLR1. Quantitative RT-PCR was used to measure the effect of increased nuclear TBLR1 on the transcription of a set of androgen-regulated genes. AR target genes are involved in a broad spectrum of variable cellular processes including cell-cycle progression, tumor suppression, differentiation, and apoptosis. We selected a limited number of genes from different groups as examples to measure nuclear TBLR1 effects on AR-mediated transcriptional activation. This panel contained an assortment

siRNA or control siRNA in 10 nM R1881 media shows decreased growth after AR knockdown. (D) Proliferation assay of LNCaP NLSTBLR1 cells treated with AR siRNA or control siRNA in $10 \mathrm{nM}$ R1881 media shows increased growth after AR knockdown. The growth measurments were performed in triplicate in two independent experiments. ${ }^{*}, P<0.05$.

of exemplary androgen-regulated genes in various categories including CCNA2 (Cyclin A2) and CDC6 (promoting cell-cycle activation), HUS1 (involved in cellcycle arrest), NKX3-1 (prostate-specific tumor suppressor), and KRT18 (luminal epithelial differentiation).

We compared gene expression between LNCaP NLSTBLR1 and LNCaP pBabe control cells after stimulation with androgen. The panel of genes we tested was divided into two groups. Genes that showed $>1.7$-fold activation by NLSTBLR1 in set 1 (Fig. 6A and B) and genes that showed little to no activation in set 2 (Supplementary Fig. 8A, see section on supplementary data given at the end of this article). Subset 1 included genes primarily associated with growth suppression/differentiation, including NKX3-1, PMEPA1, HUS1, and KRT18. These genes were confirmed to be androgen-regulated in our assay by comparing hormone-free with androgencontaining media in LNCaP control cells (Supplementary Fig. $8 \mathrm{~B}$ ). In addition, $B M P R 1 B$, a gene associated with reduced expression in prostate cancer (Kim et al. 2000) also showed activation. JAG1, the ligand for Notch1 receptor and suggested to have both oncogenic and tumor suppressor roles in varying tumor types, was highly upregulated by increased TBLR1. Subset 2, which showed

Published by Bioscientifica Ltd. 


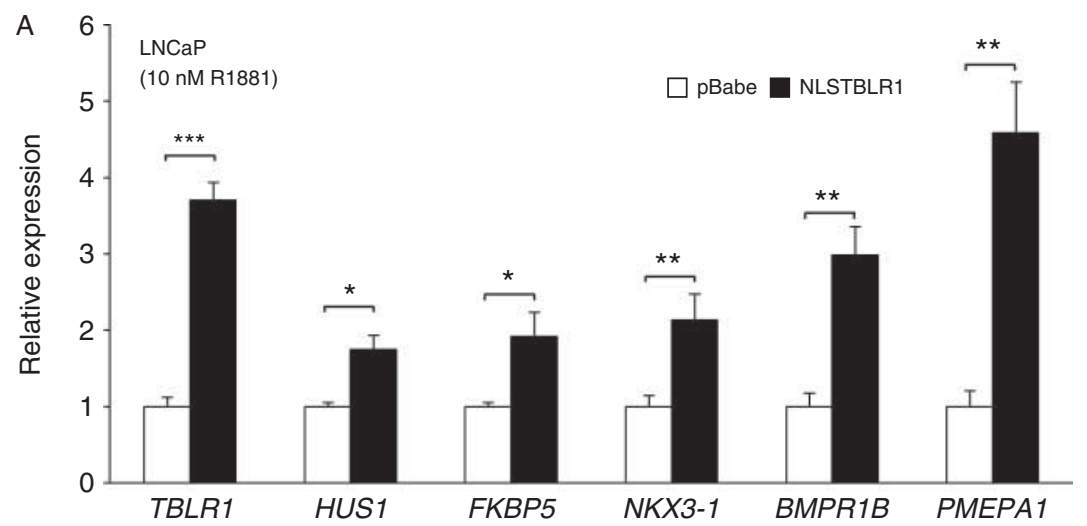

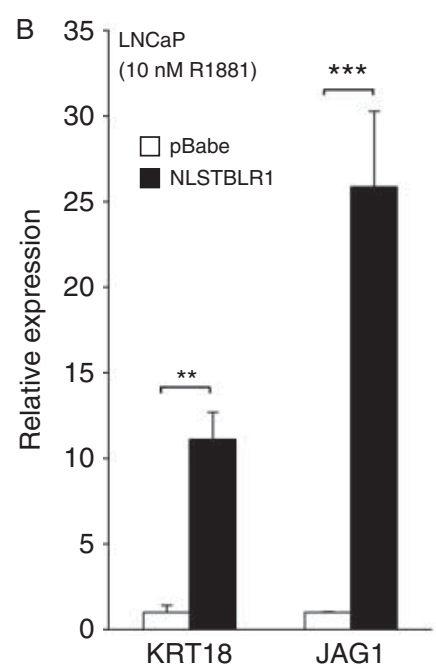

\section{Figure 6}

Nuclear TBLR1 upregulates growth suppressive AR target genes. (A and B) Comparison of expression of androgen-regulated genes between LNCaP pBabe and LNCaP NLSTBLR1 in $10 \mathrm{nM}$ R1881 media by qRT-PCR. The figure is divided between genes for which expression was increased less than tenfold (A) and genes in which expression was increased more than tenfold

little to no activation from overexpression of NLSTBLR1, included genes primarily associated with cell proliferation, including CCNA2 and CDC6 (Supplementary Fig. 8A).

Changes in the expression of NKX3-1, KRT18, HUS1, and JAG1 after nuclear TBLR1 overexpression were also confirmed at the protein level by western blot. In addition, we tested expression of the androgen-regulated cell-cycle regulators p27 and p21. Overexpression of nuclear TBLR1 had no effect on p21, but there was a strong increase in p27 expression, suggesting a role of p27 in growth arrest initiated by nuclear TBLR1 (Fig. 6C). In addition, we tested the effect of increased nuclear TBLR1 on p27 levels in two additional androgen-sensitive cell lines, RC165 and LNCaP-AI. Overexpression of nuclear TBLR1 also led to

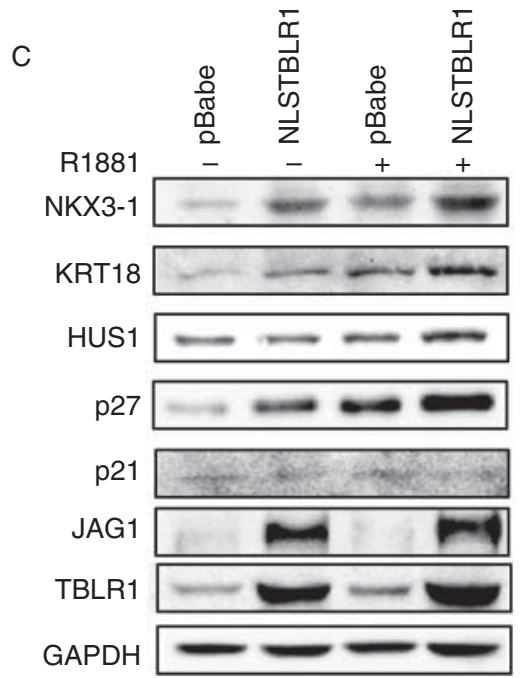

(B) in LNCaP NLSTBLR1 cells compared with LNCaP pBabe cells in the presence of $10 \mathrm{nM}$ R1881. (C) Comparison of protein expression of androgen-regulated genes between LNCaP pBabe and LNCaP NLSTBLR1 in hormone-free media or $10 \mathrm{nM}$ R1881 media by western blot. ${ }^{*} P<0.05$, $* *, P<0.01, * * *, P<0.001$

increased p27 protein levels by western blot analysis in these cells (Supplementary Fig. 8C).

To further confirm these results of TBLR1 acting as a coactivator of AR, we also tested the effect of TBLR1 knockdown across this panel of genes. Loss of TBLR1 led to a reduction in expression across the panel of genes (Supplementary Fig. 9A, see section on supplementary data given at the end of this article). Loss of NKX3-1, $K R T 18$, and HUS1 expression at the protein level was confirmed (Supplementary Fig. 9B). No change in p27 levels was observed upon TBLR1 knockdown.

We next used chromatin immunoprecipitation (ChIP) to test the direct regulation of the affected AR target genes by TBLR1. NKX3-1 has been confirmed to be a direct AR 
A

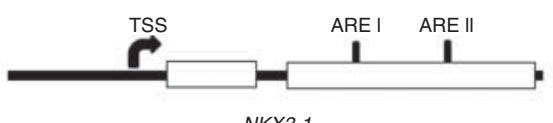

B

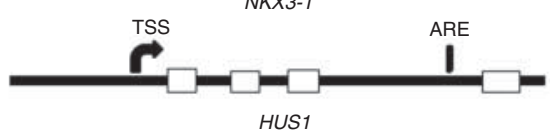

C

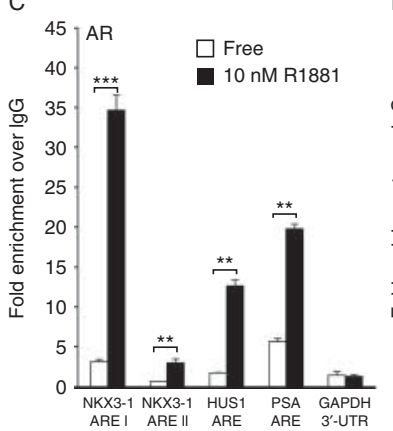

D

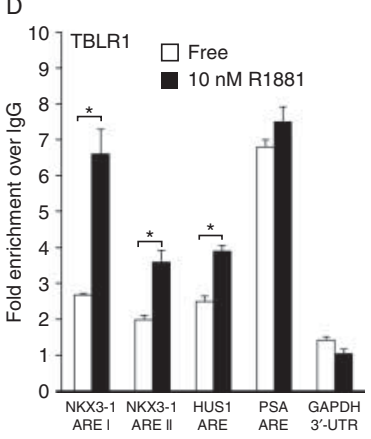

Figure 7

TBLR1 occupancy on growth suppressive AR target genes. (A) Diagram of androgen response element(s) (ARE) on NKX3-1 gene and (B) HUS1 gene. (C) Chromatin immunoprecipitation (ChIP) with AR antibody in LNCaP cells in hormone free or $10 \mathrm{nM}$ R1881 media at NKX3-1 ARE I, and ARE II, HUS1 ARE, PSA ARE, and GAPDH 3'-UTR negative control to confirm ARE at each of the AR target genes. (D) ChIP with TBLR1 antibody in LNCaP cells in hormone free or $10 \mathrm{nM}$ R1881 media at NKX3-1 ARE I, ARE II, HUS1 ARE, PSA ARE, and GAPDH $3^{\prime}$-UTR negative control. All experiments were performed in triplicate. ${ }^{*}, P<0.05, * *, P<0.01, * * *, P<0.001$.

target gene with the primary ARE identified within the 3'-UTR of the gene (Thomas et al. 2010). There is also an ARE for the HUS1 gene between exons 3 and 4 (see Fig. 7A and $\mathrm{B})$. In addition, we used the well-characterized AR target gene, prostate-specific antigen, PSA (KLK3) as a positive control. By ChIP, using antibody specific to AR, we first confirmed these $4 \times$ ARE by increased occupation of AR by androgen stimulation (Fig. 7C). Using a polyclonal antibody specific to TBLR1, we showed TBLR1 occupancy at both the primary and secondary ARE of the NKX3-1 gene, HUS1 ARE, and PSA ARE but not at the GAPDH 3'-UTR negative control. Upon androgen stimulation, TBLR1 occupancy at both ARE of NKX3-1 increased over twofold. We also showed TBLR1 occupancy on the ARE of the HUS1 gene with an increase by $~ 1$.4-fold upon androgen stimulation. Androgen stimulation did not show increased TBLR1 at the PSA promoter, corresponding with its lack of activation, observed in LNCaP cells, by increased nuclear TBLR1 (Fig. 7D).

As we had determined that increased nuclear TBLR1 led to increased activation of NKX3-1 and HUS1 genes in the presence of androgen, we next tested if increased nuclear TBLR1 modified occupancy of the corepressor
NCoR at regulatory elements after androgen stimulation. We compared LNCaP NLSTBLR1 cells and LNCaP pBabe control cells by ChIP analysis using a polyclonal NCoR antibody. There was significantly reduced NCoR occupancy at the NKX3-1 AREI and the HUS1 ARE in LNCaP NLSTBLR1 cells compared with LNCaP pBabe control cells after androgen stimulation (Supplementary Fig. 10A and $\mathrm{B}$, see section on supplementary data given at the end of this article).

\section{Discussion}

AR signaling is critical for prostate cancer growth and progression. Transcriptional cofactors, including both coactivators and corepressors, are important in the regulation of AR transcriptional activity. Tumor development and progression are affected by changes in expression, localization, and activation of various cofactors. In this study, we examined the role of the nuclear receptor cofactor, TBLR1, as a regulator of AR transcriptional activity and its expression and function in prostate cancer.

TBLR1 is ubiquitously expressed and has been shown to serve as a corepressor for a number of transcription factors of the NHR family, serving as a docking function for NCoR and SMRT. These interact with HDAC3 to form an active deacetylase and render chromatin less accessible. Little is known about the interactions of TBLR1 with AR and their ensuing function in prostate cancer. We showed that TBLR1 acts as a coactivator of $\mathrm{AR}$ in prostate cancer cells by both luciferase assay and AR target gene expression. TBLR1 interacts with AR in an androgen-dependent manner and directly cooccupies ARE with AR.

Overwhelming evidence in the literature indicates the importance of AR transcriptional activation in driving prostate cancer cell proliferation. Recently, a number of AR coactivators have been shown to have tumor suppressor effects, including ARA70 $\alpha$ and nuclear p44/MEP50 (Peng et al. 2008a, Ligr et al. 2010). Understanding the balance between proliferation and growth suppression, and the role specific cofactors play in the regulation of this switch is critical in understanding prostate biology and prostate cancer treatment methods. The benign prostate cancer cell line, RC165, has high nuclear TBLR1 expression compared with the cancer cell line LNCaP. As observed in our cell line model, human tumor samples show significant reduction in TBLR1 in the nucleus of malignant glands in comparison with the neighboring benign glands. In addition, serum-starvation-

Published by Bioscientifica Ltd. 
induced growth arrest leads to the translocation of TBLR1 from the cytoplasm to the nucleus in cancer cells. These data together strongly indicate a role of nuclear TBLR1 as a tumor suppressor in prostate cancer. Interestingly, although overall level of expression of TBLR1 is reduced in cancerous vs benign cells, we observed a correlation of increased nuclear TBLR1 with increased Gleason score. This could be indicative of a feedback mechanism in which higher grade cancers' cells are producing more TBLR1 in an unsuccessful attempt to control cancer cell proliferation.

Indeed, overexpression of nuclear TBLR1 in ARpositive prostate cancer cells leads to growth suppression in vitro in cell proliferation and anchorage-independent assays, as well as tumor growth inhibition in nude mice xenografts in vivo. It appears that there is an androgenindependent component of tumor suppression by TBLR1 also, because the growth of LNCaP cells is reduced even in growth medium free of androgen (Fig. 3B). Importantly, there is a higher degree of androgen-dependent element of growth inhibition as nuclear TBLR1 promotes cell growth in PC3 cells and this process is reversed to growth inhibition in PC3-AR cells (Fig. 5A and B). To confirm an androgen-dependent mechanism of nuclear TBLR1mediated growth inhibition, AR knockdown in LNCaP NLSTBLR1 cells was also able to partially rescue growth suppressive effects (Fig. 5C and D).

AR can regulate selected sets of AR target genes (Agoulnik \& Weigel 2009, Wang et al. 2011) under various conditions. A number of AR target genes have been shown to regulate cell growth including cell-cycle genes, apoptosis, tumor suppressors, and differentiation genes. In this study, we have shown that TBLR1 is an AR coactivator that acts as a tumor suppressor in prostate cancer cells by selectively activating growth suppression and differentiating androgen-regulated genes. Overexpressing nuclear TBLR1 in the prostate cancer model cell line LNCaP leads to increased expression of important prostate prodifferentiation (i.e. KRT18) and tumor suppressor genes (i.e. NKX3-1 and HUS1). Overexpression of nuclear TBLR1 in LNCaP cells also leads to increased expression of the cell-cycle inhibitor P27 (CDKN1B), an androgen regulated gene which may be responsible for the G0/G1 cell-cycle arrest observed in our proliferation studies. Increased expression of NKX3-1 and P27 has been previously reported to work synergistically to decrease prostate cancer cell proliferation (Wang et al. 2009). Our data indicate that TBLR1 interacts with $A R$ in an androgen-dependent manner, and that TBLR1 directly occupies ARE of AR target genes NKX3-1 and HUS1 in an androgen-dependent manner. Together, these data indicate that nuclear TBLR1 is a direct regulator of growth-suppressive AR target genes.

Interestingly, upon knockdown of TBLR1 in LNCaP or LNCaP-AI cells by siRNA, we also observed a reduction in proliferative ability, showing that either overexpression or knockdown of TBLR1 leads to G0/G1 growth arrest. Although these data at first seem contradictory, it appears that the growth arrest observed in each of these instances could be through different mechanisms. Overexpression of TBLR1 showed increased p27 levels whereas knockdown of TBLR1 did not affect p27 levels (Fig. 6C and Supplementary Fig. 9B). In addition, we showed that overexpression of nuclear TBLR1 leads to selective activation of growth suppression/differentiation AR target genes but not proproliferative genes (Fig. 6A); however, knockdown of TBLR1 leads to a more global downregulation of both sets of genes (Supplementary Fig. 9A). This shows that although increased nuclear TBLR1 does selectively activate a subset of AR target genes, a baseline level may be required for most AR target genes and cell proliferation. It is possible that the loss of expression of proliferation genes (i.e. CCNA2 and CDC6) upon TBLR1 knockdown overrides the effect of decreased tumor suppressor target genes (i.e. NKX3-1) on overall growth rate. In addition, as TBLR1 functions in the context of a protein complex with HDAC and NCoR proteins, loss of expression of the TBLR1 component may disrupt the complex and interfere with transcription and cell growth.

Previous studies have shown that the mechanism of TBLR1 activation of nuclear receptors could be due to phosphorylation of TBLR1 by PKC $\delta$ at two specific sites that target NCoR for ubiquitination and degradation by the $19 \mathrm{~S}$ proteosome (Perissi et al. 2004). In prostatic tissues we showed by luciferase assay that activation of AR by TBLR1 also is dependent on both $19 \mathrm{~S}$ proteosome activity and phosphorylation (Fig. 1C, D and E). Indirect evidence has suggested that TBLR1 serves as an F-box protein with E3 ligase activity on BCL3 (Keutgens et al. 2010). It has been suggested that as it contains an F-box like motif, it acts as an E3 ligase and promotes the degradation of NCoR, leading to increased chromatin accessibility. The F-box in TBLR1 is unusual, in that it lacks a tryptophan near the NH2-end of the motif that is required for Skp1 binding (Kipreos \& Pagano 2000). Without this interaction E3 ligase activity does not develop. However, no interaction of TBLR1 with SKP1 could be demonstrated by our laboratory (Daniels \& Lee, unpublished data 2013), indicating that the role of TBLR1 in the proteosome pathway may be indirect. When we tested LNCaP NLSTBLR1 phospho-mutants in

Published by Bioscientifica Ltd 
proliferation assays, however, there was no difference in growth observed between NLSTBLR1 and all three phospho-mutants, revealing that phosphorylation at these sites alone is not critical for growth suppression by nuclear TBLR1 (Supplementary Fig. 3E), supported by our data indicating that phospho-mutants still retain some coactivation ability in our luciferase assay (Fig. 1F). Phosphorylation of TBLR1 may affect functions of TBLR1 other than growth inhibition. A recent report has also shown that TBLR1 is sumolyated at K497 and therefore required for activation of Wnt target genes through interaction with $\beta$-catenin (Choi et al. 2011). However, using a sumolyation mutant K497R TBLR1 plasmid in our luciferase assay, we observed equal AR activation compared with WT TBLR1 (Supplementary Fig. 1A). Sumolyation at K497 does not appear to be important for AR transcriptional activation in our limited luciferase system.

In conclusion, nuclear TBLR1 acts as a tumor suppressor in prostate cancer and AR coactivator directly and selectively activates androgen-regulated genes important for growth suppression/differentiation. Better understanding of AR regulation in the prostate and the molecular switches that occur in transition from growth suppression to proproliferation target genes will lead to more successful prostate cancer treatments.

\section{Supplementary data}

This is linked to the online version of the paper at http://dx.doi.org/10.1530/ ERC-13-0293.

\section{Declaration of interest}

The authors declare that there is no conflict of interest that could be perceived as prejudicing the impartiality of the research reported.

\section{Funding}

This study is supported by the National Institutes of Health (NIH) (1U01CA149556-01), Department of Defense Prostate Cancer Research Program (DOD PCRP) (PC080010 and PC11624), and VA Merit (1101BX001505-01) grants to P Lee, New York University Clinical and Translational Science Institute (NYU CTSI) TL1 (1UL1RR029893) and NYU Molecular Oncology and Immunology Training grant (T32 CA009161) postdoctoral fellowships to G Daniels, DOD postdoctoral fellowship (PC081578) to Y Li and (PC094557) X Wu.

\section{Acknowledgements}

This material is based on work supported in part by the Department of Veterans Affairs, Veterans Health Administration, Office of Research and Development (Biomedical Laboratory Research and Development). The authors thank the Department of Defense supported Prostate Cancer Biorepository Network (PCBN).

\section{References}

Agoulnik IU \& Weigel NL 2009 Coactivator selective regulation of androgen receptor activity. Steroids 74 669-674. (doi:10.1016/ j.steroids.2009.02.007)

Altuwaijri S, Wu CC, Niu YJ, Mizokami A, Chang HC \& Chang C 2007 Expression of human AR cDNA driven by its own promoter results in mild promotion, but not suppression, of growth in human prostate cancer PC-3 cells. Asian Journal of Andrology 9 181-188. (doi:10.1111/ j.1745-7262.2007.00258.x)

Burke LJ \& Baniahmad A 2000 Co-repressors 2000. FASEB Journal 14 1876-1888. (doi:10.1096/fj.99-0943rev)

Cai CQ, Peng Y, Buckley MT, Wei J, Chen F, Liebes L, Gerald WL, Pincus MR, Osman I \& Lee P 2008 Epidermal growth factor receptor activation in prostate cancer by three novel missense mutations. Oncogene 27 3201-3210. (doi:10.1038/sj.onc.1210983)

Choi HK, Choi KC, Yoo JY, Song M, Ko SJ, Kim CH, Ahn JH, Chun KH, Yook JI \& Yoon HG 2011 Reversible SUMOylation of TBL1-TBLR1 regulates $\beta$-catenin-mediated Wnt signaling. Molecular Cell 43 203-216. (doi:10.1016/j.molcel.2011.05.027)

Dehm SM \& Tindall DJ 2006 Molecular regulation of androgen action in prostate cancer. Journal of Cellular Biochemistry 99 333-344. (doi:10.1002/jcb.20794)

Gao M, Ossowski L \& Ferrari AC 1999 Activation of Rb and decline in androgen receptor protein precede retinoic acid-induced apoptosis in androgen-dependent LNCaP cells and their androgen-independent derivative. Journal of Cellular Physiology 179 336-346. (doi:10.1002/ (SICI)1097-4652(199906)179:3 <336::AID-JCP11>3.0.CO;2-Q)

Garcia-Arenas R, Lin FF, Lin D, Jin LP, Shih CC, Chang C \& Lin MF 1995 The expression of prostatic acid phosphatase is transcriptionally regulated in human prostate carcinoma cells. Molecular and Cellular Endocrinology 111 29-37. (doi:10.1016/0303-7207(95)03544-H)

Gelmann EP 2002 Molecular biology of the androgen receptor. Journal of Clinical Oncology 20 3001-3015. (doi:10.1200/JCO.2002.10.018)

Gu Y, Kim KH, Ko D, Srivastava S, Moul JW, McLeod DG \& Rhim JS 2005 Androgen and androgen receptor antagonist responsive primary African-American benign prostate epithelial cell line. Anticancer Research 25 1-8.

Heinlein CA \& Chang C 2002 Androgen receptor (AR) coregulators: an overview. Endocrine Reviews 23 175-200. (doi:10.1210/er.23.2.175)

Janne OA, Moilanen AM, Poukka H, Rouleau N, Karvonen U, Kotaja N, Hakli M \& Palvimo JJ 2000 Androgen-receptor-interacting nuclear proteins. Biochemical Society Transactions 28 401-405. (doi:10.1042/ 0300-5127:0280401)

Keutgens A, Shostak K, Close P, Zhang X, Hennuy B, Aussems M, Chapelle JP, Viatour P, Gothot A, Fillet $\mathrm{M}$ et al. 2010 The repressing function of the oncoprotein BCL-3 requires CtBP, while its polyubiquitination and degradation involve the E3 ligase TBLR1. Molecular and Cellular Biology 30 4006-4021. (doi:10.1128/MCB.01600-09)

Kim IY, Lee DH, Ahn HJ, Tokunaga H, Song W, Devereaux LM, Jin D, Sampath TK \& Morton RA 2000 Expression of bone morphogenetic protein receptors type-IA, -IB and -II correlates with tumor grade in human prostate cancer tissues. Cancer Research $602840-2844$.

Kipreos ET \& Pagano M 2000 The F-box protein family. Genome Biology $\mathbf{1}$ REVIEWS3002. (doi:10.1186/gb-2000-1-5-reviews3002)

Li Y, Wang L, Zhang M, Melamed J, Liu X, Reiter R, Wei J, Peng Y, Zou X, Pellicer A et al. 2009 LEF1 in androgen-independent prostate cancer: regulation of androgen receptor expression, prostate cancer growth, and invasion. Cancer Research 69 3332-3338. (doi:10.1158/0008-5472. CAN-08-3380)

Ligr M, Li Y, Zou X, Daniels G, Melamed J, Peng Y, Wang W, Wang J, Ostrer H, Pagano $\mathrm{M}$ et al. 2010 Tumor suppressor function of androgen receptor coactivator ARA70a in prostate cancer. American Journal of Pathology 176 1891-1900. (doi:10.2353/ajpath.2010.090293)

Ligr M, Li Y, Logan SK, Taneja S, Melamed J, Lepor H, Garabedian MJ \& Lee P 2012 Mifepristone inhibits GR $\beta$ coupled prostate cancer cell 
proliferation. Journal of Urology 188 981-988. (doi:10.1016/j.juro.2012. 04.102)

Nwachukwu JC, Mita P, Ruoff R, Ha S, Wang Q, Huang SJ, Taneja SS, Brown M, Gerald WL, Garabedian MJ et al. 2009 Genome-wide impact of androgen receptor trapped clone-27 loss on androgen-regulated transcription in prostate cancer cells. Cancer Research 69 3140-3147. (doi:10.1158/0008-5472.CAN-08-3738)

Peng Y, Chen F, Melamed J, Chiriboga L, Wei J, Kong X, McLeod M, Li Y, Li CX, Feng A et al. 2008a Distinct nuclear and cytoplasmic functions of androgen receptor cofactor p44 and association with androgenindependent prostate cancer. PNAS 105 5236-5241. (doi:10.1073/ pnas.0712262105)

Peng Y, Li CX, Chen F, Wang Z, Ligr M, Melamed J, Wei J, Gerald W, Pagano M, Garabedian MJ et al. 2008b Stimulation of prostate cancer cellular proliferation and invasion by the androgen receptor co-activator ARA70b. American Journal of Pathology 172 225-235. (doi:10.2353/ajpath.2008.070065)

Perissi V, Aggarwal A, Glass CK, Rose DW \& Rosenfeld MG 2004 A corepressor/coactivator exchange complex required for transcriptional activation by nuclear receptors and other regulated transcription factors. Cell 116 511-526. (doi:10.1016/S0092-8674(04)00133-3)

Perissi V, Scafoglio C, Zhang J, Ohgi KA, Rose DW, Glass CK \& Rosenfeld MG 2008 TBL1 and TBLR1 phosphorylation on regulated gene promoters overcomes dual CtBP and NCoR/SMRT transcriptional repression checkpoints. Molecular Cell 29 755-766. (doi:10.1016/j.molcel. 2008.01.020)

Thomas MA, Preece DM \& Bentel JM 2010 Androgen regulation of the prostatic tumour suppressor NKX3.1 is mediated by its $3^{\prime}$ untranslated region. Biochemical Journal 425 575-583. (doi:10.1042/BJ20091109)

Tomita A, Buchholz DR \& Shi YB 2004 Recruitment of N-CoR/SMRT-TBLR1 corepressor complex by unliganded thyroid hormone receptor for gene repression during frog development. Molecular and Cellular Biology 24 3337-3346. (doi:10.1128/MCB.24.8.3337-3346.2004)
Wang P, Ma Q, Luo J, Liu B, Tan F, Zhang Z \& Chen Z 2009 Nkx3.1 and p27(KIP1) cooperate in proliferation inhibition and apoptosis induction in human androgen-independent prostate cancer cells. Cancer Investigation 27 369-375. (doi:10.1080/ 07357900802232749)

Wang D, Garcia-Bassets I, Benner C, Li W, Su X, Zhou Y, Qiu J, Liu W, Kaikkonen MU, Ohgi KA et al. 2011 Reprogramming transcription by distinct classes of enhancers functionally defined by eRNA. Nature $\mathbf{4 7 4}$ 390-394. (doi:10.1038/nature10006)

Whitacre DC, Chauhan S, Davis T, Gordon D, Cress AE \& Miesfeld RL 2002 Androgen induction of in vitro prostate cell differentiation. Cell Growth \& Differentiation 13 1-11.

Yoon HG, Chan DW, Huang ZQ, Li J, Fondell JD, Qin J \& Wong J 2003 Purification and functional characterization of the human N-CoR complex: the roles of HDAC3, TBL1 and TBLR1. EMBO Journal 22 1336-1346. (doi:10.1093/emboj/cdg120)

Yoon HG, Choi Y, Cole PA \& Wong J 2005 Reading and function of a histone code involved in targeting corepressor complexes for repression. Molecular and Cellular Biology 25 324-335. (doi:10.1128/ MCB.25.1.324-335.2005)

Yu SQ, Lai KP, Xia SJ, Chang HC, Chang C \& Yeh S 2009 The diverse and contrasting effects of using human prostate cancer cell lines to study androgen receptor roles in prostate cancer. Asian Journal of Andrology $\mathbf{1 1}$ 39-48. (doi:10.1038/aja.2008.44)

Yuan S, Trachtenberg J, Mills GB, Brown TJ, Xu F \& Keating A 1993 Androgen-induced inhibition of cell proliferation in an androgeninsensitive prostate cancer cell line (PC-3) transfected with a human androgen receptor complementary DNA. Cancer Research $\mathbf{5 3}$ 1304-1311.

Zhang XM, Chang Q, Zeng L, Gu J, Brown S \& Basch RS 2006 TBLR1 regulates the expression of nuclear hormone receptor co-repressors. BMC Cell Biology 7 31. (doi:10.1186/1471-2121-7-31)

Received in final form 18 October 2013

Accepted 14 November 2013

Made available online as an Accepted Preprint

15 November 2013 http://erc.endocrinology-journals.org DOI: 10.1530/ERC-13-0293
(C) 2014 Society for Endocrinology Printed in Great Britain
Published by Bioscientifica Ltd. 